\title{
Uso de acidificantes em dietas para leitões em desmame e creche
}

\author{
Denck, F.M.; Hilgemberg, J.O. e Lehnen, C.R. ${ }^{@}$
}

Grupo Biologia Integrativa e Modelagem na Produção de Não Ruminantes. Universidade Estadual de Ponta Grossa. Ponta Grossa, PR. Brasil.

\section{PalaVRas ChAVE ADICIONAIS}

Aditivos.

Ácidos orgânicos.

Suínos.

\section{RESUMO}

Desordens fisiológicas associadas a imaturidade gastrintestinal e a limitada produção de ácidos e enzimas digestivas aumentam a incidência de diarreias em leitões pós-desmame. Os acidificantes têm sido amplamente explorados como aditivos melhoradores de desempenho. $\bigcirc$ objetivo desta revisão é relacionar as principais características físicas, mecanismos de ação e a eficiência de utilização dos acidificantes com as respostas obtidas com o seu uso em dietas para leitões pós-desmame e em creche. $\bigcirc$ uso de acidificantes em dietas para leitões na fase de desmame e creche melhora a condição sanitária e o desempenho. As ações positivas do uso estão associadas a redução do pH gástrico, controle da microbiota intestinal e estimulo na secreção de enzimas digestivas. Como resultado, os ácidos orgânicos e sais podem melhorar o ganho de peso e a eficiência alimentar. Os ácidos fórmico, propiônico, butírico, lático, sórbico, benzoico, fumárico, málico, cítrico, e os sais formato de cálcio, lactato de cálcio, propionato de cálcio, diformato de potássio, butirato de sódio, citrato de magnésio e lactato de sódio podem ser utilizados na alimentação, embora os ácidos benzoico, fumárico, butírico e sais destes ácidos apresentam um maior número de informações na literatura. $\mathrm{O}$ uso conjunto de ácidos orgânicos e sais, além dos blends, ambos administrados na forma cristalina, livre ou protegidos, apresentam os melhores resultados para leitões em creche.

\section{Acidifiers in diets for weanling and nursery piglets}

\section{SUMMARY}

\section{ADDITIONAL KEYWORDS}

Additives.

Organicacids.

Pigs.

\section{INFORMATION}

\section{Cronología del artíiculo.}

Recibido/Received: 08.07.2016

Aceptado/Accepted: 13.07.2016

On-line: 15.10 .2017

Correspondencia a los autores/Contact e-mail:

cheilalehnen@gmail.com

\section{INTRODUÇÃO}

Atualmente, na suinocultura moderna o desmame dos leitões ocorre entre 21 e 28 dias de idade, considerado precoce em relação ao desmame natural (Silva et al., 2014). O desmame é considerado um dos momentos mais críticos para o desenvolvimento do leitão. Dentre
Physiological disorders associated with gastrointestinal immaturity and limited production of digestive acids and enzymes increase the incidence of diarrhea in post-weaning piglets. Acidifying agents have been widely exploited as performance enhancing additives. The objective of this review is to relate the main physical characteristics, mechanisms of action and the efficiency of use of acidifiers with the responses obtained from their use in diets for piglets and post-weaning nurseries. The use of acidifiers in diets for piglets in weaning and nursery stages improves the sanitary condition and performance. The positive actions of the use are associated with reduction of gastric $\mathrm{pH}$, control of the intestinal microbiota and stimulation in the secretion of digestive enzymes. As a result, organic acids and salts can improve weight gain and feed efficiency. Formic, a, propionic, butyric, lactic, sorbic, benzoic, fumaric, malic, citric acids and the calcium formate citrate and lactate Can be used in food, although the acids: benzoic, fumaric, butyric and salts of these acids present a greater number of information in the literature. The combined use of organic acids and salts, in addition to blends, both administered in crystalline form, free or protected, present the best results for piglets in day care. salts, calcium lactate, calcium propionate, potassium diformate, sodium butyrate, magnesium as características dos leitões nesta fase estão a insufide absorção devido à arquitetura dos vilos, a secreção gástrica mal desenvolvida e o baixo consumo de ração, fatores estes que limitam o crescimento do animal até a fase de terminação (Corassa, 2004). Além disso, os leitões passam por mudanças drásticas no ambiente ciência das enzimas digestivas, a reduzida capacidade 
como a perda de contato com a mãe, adaptação a um novo espaço físico, integração social, alteração da dieta líquida para sólida e transição de refeições pequenas e frequentes para refeições maiores e menos frequentes (Morais, 2009).

Em busca de soluções para os problemas gerados pós-desmama, uma das formas de obter respostas produtivas do leitão é o fornecimento de alimentos sólidos antes da desmama, assim ele já estará mais adaptado às novas condições. Outra tentativa foi o fornecimento de antibióticos como bacteriostáticos ou bactericidas, mas esta alternativa tornou-se um grande desafio na suinocultura pelo fato de que o uso indiscriminado destes produtos levou a resistência das bactérias ao princípio ativo, podendo afetar tanto os leitões quanto os homens. De modo que, a União Europeia, em 1998 proibiu o uso destas substâncias (Brumano e Gattás, 2009), levando a investigação de novas alternativas, tais como os acidificantes.

O principal efeito dos acidificantes quando adicionado à dieta de leitões é alterar o pH estomacal, inibindo o desenvolvimento de microrganismos patogênicos e indiretamente, reduzir a incidência de diarréias (Grecco, 2014). Estudos ainda indicam que os acidificantes podem influenciar no crescimento das vilosidades intestinais, reduzindo à frequência de diarreia e melhorado o desempenho de leitões (Chiquieri et al., 2009; Chamone et al., 2010). Dentre os acidificantes mais utilizados destacam-se os ácidos orgânicos benzoico, butírico, fumárico e seus sais (Hilgemberg et al., 2015) os quais podem ser adicionados na dieta em pó ou misturados na água de bebida.

Diante do exposto, nesta revisão serão abordadas as principais características, o mecanismo de ação e a eficiência de utilização dos acidificantes, além dos resultados obtidos com o seu uso em dietas para leitões pós-desmame e em creche.

\section{FISIOLOGIA DIGESTIVA DE LEITÕES AO DESMAME E EM CRECHE}

O desmame é o processo de separação dos leitões da mãe que ocorre geralmente aos 21 dias de idade, a fim de aumentar a produtividade das matrizes e otimizar o uso das instalações. Associadas ao processo de desmame ocorrem mudanças histológicas, bioquímicas, fisiológicas, nutricionais e socioambientais que comprometem o desempenho dos leitões (Silva, 2014). As principais alterações ocorrem em nível histológico e fisiológico, como alteração da mucosa intestinal, atrofia de vilosidades e hiperplasias de criptas, que diminuem as capacidades absortivas e digestivas do intestino delgado dos leitões logo após desmame. A substituição da alimentação líquida por sólida, e novos componentes adicionados à dieta de leitões pós-desmame, associados ao novo ambiente favorecem ao estresse fisiológico ocasionando diarréias (Grecco, 2014).

Do nascimento ao desmame, o sistema digestivo dos leitões está adaptado a digerir o leite e não alimentos sólidos, principalmente os de origem vegetal (Chamone et al., 2010). Durante o período de aleitamento o principal acidificante do estômago do leitão é o ácido lático produzido pela fermentação da lactose, que é alta do nascimento até por volta da segunda e terceira semana de vida, declinando rapidamente. A produção de ácido clorídrico é mínima nos leitões e de forma gradual cresce a partir da quarta até a oitava semana de vida (figura 1). Desta forma, tem-se a transição do ácido lático para o ácido clorídrico, na acidificação do estômago. Porém, nessa fase o ácido clorídrico produzido não tem a sua máxima eficiência levando a um quadro de $\mathrm{pH}$ superior ao desejado para a ativação de enzimas proteolíticas e controle de microrganismos patogênicos (Morais, 2009).

Os leitões desmamados precocemente apresentam o sistema gastrointestinal imaturo, a produção de ácido clorídrico é baixa e a principal fonte de acidez é a fermentação bacteriana da lactose do leite em ácido láctico. Um nível elevado de lactato no estômago tende a inibir a secreção de ácido clorídrico e consequentemente secreção enzimática insuficiente (Suryanarayana et al., 2015).

\section{PropRIEDADE FÍSICO-QUÍMICAS DOS ACIDIFICANTES}

Os acidificantes pertencem ao grupo de aditivos equilibradores da flora, podem ser ácidos orgânicos e seus sais ou ácidos inorgânicos. Os ácidos orgânicos são formados por átomos de carbono, hidrogênio e oxigênio, que possuem o grupamento carboxila $\left(\mathrm{COOH}^{-}\right)$, são fracos e de cadeias curtas, dentre um a sete átomos de carbono (Braz, 2007). Já os ácidos inorgânicos, considerados fortes, não possuem carbono em suas moléculas, e quando em solução aquosa ionizam-se liberando $\mathrm{H}^{+}$. Na tabela I, encontram-se as principais características físico-químicas dos acidificantes.

Os ácidos orgânicos são encontrados facilmente na natureza constituindo plantas e tecidos animais, usados há décadas como conservantes e na prevenção de fungos nos alimentos. Muitos deles estão disponíveis como sais de sódio, potássio ou cálcio, que se comparados aos ácidos livres, possuem como vantagem serem inodoros e de fácil manipulação durante a fabricação da ração, devido a sua forma sólida, menos volátil e corrosiva. Além disso, sais orgânicos apresentam menor impacto negativo sobre o consumo de alimento

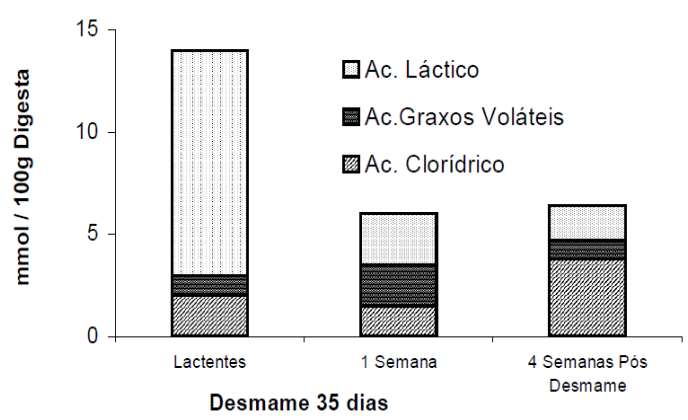

Figura 1. Concentrações de ácidos orgânicos e ácido clorídrico na digesta estomacal de leitões, três horas após a alimentação (Pupa, 2008) (Concentrations of organic acids and hydrochloric acid in the stomach digesta of piglets three hours after feeding). 
Tabela I. Propriedades físico-químicas de alguns ácidos orgânicos e seus sais (Physic-chemical properties of some organic acids and their salts).

\begin{tabular}{|c|c|c|c|c|c|c|}
\hline Nome $^{1}$ & Forma física ${ }^{2}$ & Peso molecular & EB Kcal $/ \mathrm{kg}$ & $\mathrm{pK}_{\mathrm{a}}$ & Taxa de corrosão ${ }^{3}$ & Odor \\
\hline Fórmico* & $L$ & 46,03 & 1,361 & 3,75 & $++(+)$ & $\mathrm{C}$ \\
\hline Acético* & L & 60,05 & 3,487 & 4,76 & +++ & C \\
\hline Propiônico* & $\mathrm{AL}$ & 74,08 & 4,920 & 4,88 & ++ & C \\
\hline Butírico* & $\mathrm{AL}$ & 88,12 & 5,923 & 4,82 & + & $\mathrm{R}$ \\
\hline Lático* & L & 90,08 & 3,306 & 3,86 & $(+)$ & LA \\
\hline Sórbico* & $S$ & 112,1 & 6,652 & 4,76 & $(+)$ & A \\
\hline Benzoico* & $S$ & 122,12 & 6,317 & 4,21 & $0 \mathrm{a}(+)$ & B \\
\hline Fumárico** & S & 116,1 & 2,747 & $3,02 / 4,38$ & $0 \mathrm{a}(+)$ & $\mathrm{N}$ \\
\hline Málico** & L/S & 134,1 & 2,388 & $3,46 / 5,1$ & $(+)$ & M \\
\hline Cítrico*** & $S$ & 192,1 & 2,436 & $3,1 / 4,8 / 6,4$ & $0 \mathrm{a}++$ & $\mathrm{N}$ \\
\hline Formato-Ca ${ }^{\Delta}$ & $S$ & 130,1 & 2,627 & - & 0 & $\mathrm{~N}$ \\
\hline Lactato-Ca ${ }^{\Delta}$ & $S$ & 308,3 & 7,165 & - & 0 & $\mathrm{~N}$ \\
\hline Propionato-Ca ${ }^{\Delta}$ & S & 184,1 & 9,554 & - & 0 & $\mathrm{~N}$ \\
\hline Diformato-K ${ }^{\Delta}$ & $S$ & 130,0 & 2,723 & - & 0 & $N$ \\
\hline Butirato-Na ${ }^{\Delta}$ & $S$ & 214,0 & 11,464 & - & 0 & $\mathrm{R}$ \\
\hline Citrato-Mg ${ }^{\Lambda}$ & $S$ & 214,4 & 2,388 & - & 0 & $N$ \\
\hline Lactato-Na ${ }^{\Delta}$ & $S$ & 112,1 & 3,583 & - & 0 & $\mathrm{~N}$ \\
\hline
\end{tabular}

${ }^{1 *}$ Monocarboxílico; **dicarboxílico; ***tricarboxílico; $\Delta$ sais orgânicos.

${ }^{2} \mathrm{~L}$ : Líquido; AL: Apenas líquido; S: Sólido.

${ }^{3} \mathrm{CR}=$ Taxa de corrosão: +++: alta, ++: média, +: baixa, 0 insignificante.

${ }^{4}$ C: Cáustico; R: Rançoso; LA: Leite azedo; A: Acre; B: Benzaldeído; N: Neutro; M: Maçã.

pKa = constante de dissociação; EB = Energia bruta

Fonte: Mroz (2005).

quando empregados em níveis elevados na dieta (Braz, 2007).

Os ácidos orgânicos podem se apresentar em duas formas: não dissociada $(\mathrm{RCOOH})$ ou dissociada (RCOO). Para medir a força do ácido usa-se a constante de dissociação pKa, que é a medida quando o ácido encontra-se $50 \%$ dissociado e $50 \%$ indissociado em solução aquosa com o mesmo valor de $\mathrm{pH}$. Quanto mais próximo o valor de pKa a 1 mais forte é o ácido (Vilas Boas, 2014). Outra característica importante dos acidificantes é que eles podem ser utilizados como fonte energética pelas células intestinais. Um grande exemplo disso são os ácidos graxos voláteis (ácido acético, propiônico, butírico) produtos da fermentação dos alimentos pela microbiota intestinal dos suínos. Além disso, sais como opropionato de cálcio e butirato de sódio apresentam uma relevante contribuição energética quando adicionados às dietas.

\section{OS ACIDIFICANTES MAIS UTIUZADOS NA SUINOCULTURA}

\section{ÁCIDO BENZOICO E BENZOATOS}

O ácido benzoico é um ácido carboxílico aromático, presente de forma natural em frutas frescas como o morango, e em especiarias, tais como o cravo e o azeite de anis. Esse ácido foi obtido pela primeira vez no começo do século XVII por Scheele, por meio da sublimação da goma de benzoína (Gheler et al., 2009). Os sais do ácido benzoico foram largamente utilizados como fármacos, agindo como antipirético, antifúngico, antisséptico e também no tratamento de doenças como a tuberculose, a difteria e o reumatismo (Braz, 2007).

\section{ÁCIDO BUTíRICO E BUTIRATO}

$\mathrm{O}$ ácido butírico possui cadeia curta com quatro carbonos, saturado, líquido em temperatura ambiente $\left(\mathrm{C}_{4} \mathrm{H}_{8} \mathrm{O}_{2}\right)$. Ele é a fonte energética preferencial para as células intestinais (cerca de $70 \%$ do total de energia consumida pelos colonócitos), mesmo em presença de glicose e glutamina (Biagi et al., 2007). Os benefícios do uso do ácido butírico em leitões está relacionado ao estímulo na diferenciação celular e multiplicação de células basais, aumento na superfície de contato entre as micro vilosidades intestinais, estímulo da atividade endócrina e exócrina do pâncreas e a secreção de enzimas digestivas. Além disso, provoca a liberação de muco no cólon intestinal diminuindo o número de células armazenadoras de muco (Costa et al., 2011). Em comparação aos outros ácidos, tais como propiônico, acético ou lático, o butírico é o que tem maior capacidade de se manter na forma não dissociada e, dessa maneira, favorece os microrganismos benéficos enquanto controla os patogênicos (Machinsky et al., 2010).

$\mathrm{O}$ butirato de sódio $\left(\mathrm{C}_{4} \mathrm{H}_{7} \mathrm{O}_{2} \mathrm{Na}\right)$ é um sal derivado do ácido butírico que atua como acidificante. É muitas vezes utilizado como substituto do ácido butírico, uma vez que é sólido estável e tem um odor menos intenso, podendo ser utilizado na forma livre ou protegido (Tonel, 2009). O butiratomicro encapsulado (forma protegida) influenciará a parte posterior do trato gastrointestinal, enquanto que este composto ao não ser 
protegido, apenas afetará diretamente a parte proximal do trato digestivo (Van Immerseel et al., 2004). Como o butirato de sódio é rapidamente absorvido, sendo uma fonte de energia disponível para os colonócitos o restante dessa energia fica disponível para a fermentação bacteriana (Tonel, 2009).

\section{ÁCIDO FUMÁRICO}

O ácido fumárico é um ácido dicarboxílico (C4H4O4) podendo ser encontrado naturalmente em plantas e fungos, apresenta-se de forma sólida, como forma de pequenos cristais brancos, considerado não volátil, inodoro, com sabor azedo e pouco solúvel em água (Partanen e Mroz, 1999). Ele é considerado um ácido orgânico fraco e de cadeia curta, que possibilita sua ação como agente antimicrobiano no trato gastrointestinal de leitões, principalmente na redução do $\mathrm{pH}$ (Knarreborg et al., 2002). A utilização de ácido fumárico tem sido sugerida como um meio de redução do pH gástrico, completando esta demanda causada pela baixa produção de ácido clorídrico (Lawlor et al., 2005). Além disso, o ácido fumárico pode apresentar efeito positivo sobre a digestibilidade ileal da proteína bruta e dos aminoácidos nas dietas para leitões desmamados precocemente, e uma excelente fonte de energia prontamente disponível (Lanferdini et al., 2013).

\section{DiFORMIATO DE POTÁSSIO E FORMATO DE CÁLCIO}

O diformiato de potássio é um sal oriundo do ácido fórmico e apresenta-se na forma sólida cristalina. Ele foi desenvolvido para ser uma alternativa aos problemas de manipulação do ácido fórmico já que esse possui elevada taxa de corrosão e odor pungente (Mroz, 2005).

O formiato de cálcio também é um sal oriundo de ácido fórmico, ocorre naturalmente em alimentos, apresenta-se na forma sólida incolor, como um pó branco cristalino, quase sem odor, sendo uma fonte altamente digestível e solúvel em água (EFSA, 2013). O formiato pode ser utilizado na forma livre ou protegido, considerado como um aditivo importante por

\begin{tabular}{|c|c|}
\hline \multicolumn{2}{|c|}{$\begin{array}{l}\text { Tabela II. Relação de enzimas do metabolismo } \\
\text { intermediário de leitões e ratos que possuem sua } \\
\text { atividade aumentada em função da adição de ácido } \\
\text { orgânico na ração (Relationship of enzymes for intermediary } \\
\text { metabolism in piglets and rats that have their activity increased as } \\
\text { a function of the addition of organic acid in the feed). }\end{array}$} \\
\hline Ácido & Enzimas \\
\hline \multirow{2}{*}{ Fórmico } & a-Cetoglutarato desidrogenase \\
\hline & Glutamato-piruvato transaminase \\
\hline \multirow{4}{*}{ Fumárico } & Aspartato transferase \\
\hline & Succinato desidrogenase \\
\hline & Fumarase \\
\hline & $\begin{array}{l}\text { Transaminases (Glutamato desidrogenase, Glutama- } \\
\text { to-oxaloacetato transaminase e Glutamato-piruvato } \\
\text { transaminase). }\end{array}$ \\
\hline Cítrico & $\begin{array}{l}\text { Transaminases (Glutamato desidrogenase, } \\
\text { Glutamato-oxaloacetato transaminase e Glutama- } \\
\text { to-piruvato transaminase). }\end{array}$ \\
\hline
\end{tabular}

Fonte: Adaptado de Silva (2004). ter efeito antimicrobiano prolongado no trato gastrointestinal e melhorar o crescimento, reduzindo diarreias e promovendo uma boa saúde intestinal (Bosi et al., 2007).

\section{AÇÃO BACTERICIDA OU BACTERIOSTÁTICA}

Segundo Chiquieri et al. (2009) os acidificantes possuem ação bacteriostática ou bactericida, porque quando não dissociados podem difundir-se passivamente através da membrana celular das bactérias, dissociar-se quando o pH interno é superior à constante de dissociação (pKa), diminuindo o $\mathrm{pH}$ plasmático. Esta redução de $\mathrm{pH}$ é incompatível com certas classes de bactérias que não toleram um gradiente significativo (figura 2). Neste caso, em resposta ao estresse, coloca-se em uso uma bomba ATPase para que os prótons sejam bombeados para o exterior da célula. Nesse processo ocorre um gasto exacerbado de energia e entrada de ânions no interior celular modificando sua pressão osmótica, levando ao esgotamento e morte celular microbiana. (Chiquieri et al., 2009).

\section{ATIVIDADE ENZIMÁTICA}

A imaturidade do sistema digestório dos leitões compromete a utilização dos alimentos, causada pela baixa capacidade de secreção do ácido clorídrico, que por sua vez, não ativará a pepsina, a qual necessita de um baixo $\mathrm{pH}$ estomacal. Até os 21-28 dias de idade, o sistema digestivo dos leitões não é capaz de produzir quantidades suficientes de lipase, amilase e protease para digerir matérias-primas de origem vegetal (Chamone et al., 2010). A ação de algumas enzimas digestivas como sacarase, maltase, tripsina, quimiotripsina e pepsina aumentam com a idade. A principal função do ácido clorídrico é a ativação da enzima pepsina que atua na digestão de proteínas. Segundo Suiryanrayna e Ramana (2015) o estômago deve apresentar pH entre 2,0 a 3,5 para que com este nível de acidez a pepsina seja ativada, proporcionando uma melhor digestão do alimento. Os produtos resultantes desta digestão, ao chegarem ao duodeno, favorecem a estimulação da secreção de bicarbonato e de enzimas pancreáticas, podendo exercer um papel na regulação do esvaziamento gástrico, além de reduzir a entrada de microrganismos potencialmente patogênicos no intestino delgado (Miguel, 2008). Portanto em um pH maior que 3,5 a pepsina não será ativada, desta forma haverá substrato proteico suficiente para o desenvolvimento de bactérias patogênicas como Escherichia colie, Salmonella spp, que secretam enterotoxinas, causando diarreia e outros distúrbios fisiológicos (Chamone et al., 2010).

A influência dos acidificantes sobre as enzimas do metabolismo intermediário foi proposta por Kirchgessner e Roth (1988), com finalidade de melhorar a utilização da energia e/ou proteína. A tabela II mostra uma relação de enzimas do metabolismo intermediário de leitões e ratos que tem suas atividades aumentadas em função da utilização dos ácidos orgânicos. 


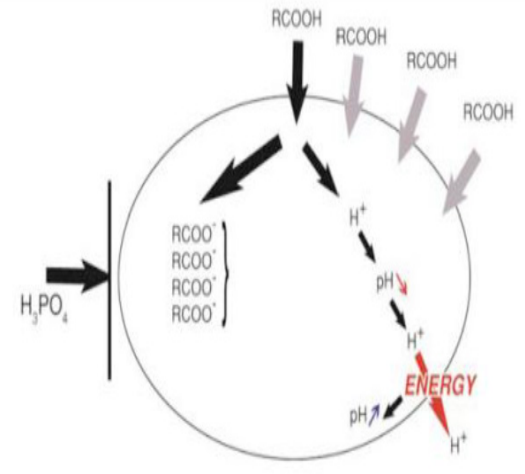

Figura 2. Modo de ação dos ácidos orgânicos sobre a membrana celular bacteriana (Gauthier, 2005) (Mode of action of organic acids on the bacterial cell membrane).

\section{MORFOMETRIA INTESTINAL}

Após o desmame dos leitões, o intestino delgado e sua mucosa perdem cerca de $25 \%$ do seu peso relativo durante os primeiros 2 dias, necessitando de 5 a 10 dias para a sua recuperação (Spreeuwenberg et al., 2001). As alterações histológicas que ocorrem no intestino delgado como consequência do desmame são a atrofia das vilosidades e hiperplasia das criptas, resultando na diminuição da capacidade digestiva e absortiva do órgão (Costa et al., 2011). Essa redução está associada à ingestão insuficiente de alimentos, digestão incompleta ou devido à presença de fatores alergênicos contidos no farelo de soja presente na maioria das dietas (Vente-Spreeuwenberg et al., 2004). Adicionalmente, a mortalidade pós-desmame também poderia estar associada ao tamanho das vilosidades e à profundidade de criptas comprometidas pelo estresse nutricional e fisiológico (Gheler et al., 2009). Por isso, uma das vantagens da utilização de acidificantes nas dietas de leitões é a sua capacidade de melhorar o epitélio intestinal, onde diversos trabalhos apresentam resultados positivos quanto a sua utilização (tabela III).

Um dos importantes efeitos do controle bacteriano é através da queda do pH em nível intestinal, uma vez que a maioria das bactérias gram-negativas colonizam em $\mathrm{pH}$ ambientes superiores a $\mathrm{pH}$ sete. Alvarado et al. (2013) e Diao et al. (2014) evidenciaram a diminuição do $\mathrm{pH}$ intestinal com o uso do ácido benzóico em dietas para leitões em creche. Este ácidose destaca por apresentar um anel aromático em sua composição química, que após sua dissociação no meio aquoso é metabolizado em ácido hipúrico, permitindo a diminuição do $\mathrm{pH}$ da urina de leitões, por meio de sua excreção (Kluge et al., 2006). A liberação de H+ acidifica o meio o que ajuda a diminuir a volatização da amônia no ambiente e a inibição de bactérias de origem vesical e vaginal, fato confirmado por estudos de Mroz et al. (2000); Torrallardona et al. (2007); Bühler et al. (2010). Porém quantoàs alterações no $\mathrm{pH}$ intestinal, grande parte dos estudos anteriormente apresentados na tabela, não indicaram mudanças significativas (Canibe et al., 2001; Kil et al., 2006; Kluge et al., 2006; Biagi et al., 2007; Halas et al., 2009; Morais, 2009; Tonel, 2009; Costa et al., 2011; Gomes et al., 2011).

Assim, os acidificantes podem reduzir a população bacteriana patogênica e ainda melhorar a morfologia intestinal. Diversos estudos apresentados na tabela III confirmam os efeitos sobre a altura das vilosidades e profundidade de criptas em leitões alimentados com dietas contendo ácidos orgânicos ou seus sais. Respostas positivas com ácido benzoico foram verificadas por Gheler et al. (2009); Halas et al. (2010) e Diao et al. (2014). A adição de formato de cálcio, tanto nas formas livre ou protegida, aumentou a altura das vilosidades do duodeno, jejuno e íleo, sem alterar a profundidade das criptas ou contagem de células no intestino delgado (Bosi et al., 2007). Já o ácido fumárico e caprílico quando adicionados à dietas de leitões desmamados modificou a estrutura da mucosa do intestino delgado (Hanczakowska et al., 2011).

Braz et al. (2011) observou melhores resultados de morfologia intestinal, favorecendo a estrutura das vilosidades, principalmente no jejuno, quando adicionado o butirato de sódio, ácido láctico e o ácido fórmico na dieta. Entretanto, alguns estudos não verificaram alterações na morfologia intestinal sendo estes justificados pela variabilidade experimental, idade dos animais, quantidade de acidificante e combinações nas dietas e

Tabela III. Efeito dos acidificantes sobre o pH e morfologia intestinal de leitões em creche (Effect of acidifiers on the $\mathrm{pH}$ and intestinal morphology by nursery piglets).

\begin{tabular}{|c|c|c|c|c|}
\hline \multirow{2}{*}{ Acidificante } & \multirow{2}{*}{$\begin{array}{l}\text { Idade, dias (ini- } \\
\text { cial-final) }\end{array}$} & \multirow{2}{*}{$\mathrm{pH}$} & \multicolumn{2}{|c|}{ Morfologia intestinal } \\
\hline & & & Altura de vilosidades & Profundidade de criptas \\
\hline Formato de cálcio & $18-58$ & & $\Delta(4)$ & $\bullet(4)$ \\
\hline Butirato de sódio & $21-58$ & $\bullet(3)(11)(20)(19)$ & $\bullet(11)(20) \boldsymbol{\Delta}(23)$ & $\bullet(11)(20)(23)$ \\
\hline Ácido benzoico & $21-70$ & $\begin{array}{c}\bullet(13)(34) \nabla(29) \\
\text { (33) }\end{array}$ & $\boldsymbol{\Delta}(7)(12)(28)(33)(35)$ & $\boldsymbol{\Delta}(12)(28) \bullet(33)(35)$ \\
\hline Diformiato de potássio & & $\bullet(26)$ & & \\
\hline Ácido fumárico & $10-70$ & $\bullet(22)(25)$ & $\begin{array}{c}\bullet(14)(17) \boldsymbol{\nabla}(25) \\
\boldsymbol{\Delta}(38)\end{array}$ & $\bullet(17) \Delta(38)$ \\
\hline
\end{tabular}

Legenda: $\boldsymbol{\Delta}$ : Aumento ( $p<0,05), \boldsymbol{\nabla}$ : Redução $(p<0,05), \bullet$ : Não alterado $(p>0,05)$.

(3) Biagi et al. (2007); (4) Bosi et al. (2007); (7) Guggenbuhl et al. (2007); (11) Morais (2009); (12) Gheler et al. (2009); (13) Kluge et al. (2006); (14) Gomes et al. (2007); (17) Grecco (2014); (19) Costa et al. (2011); (20) Tonel (2009); (22) Kil et al. (2006); (23) Lu et al. (2008); (25) Gomes et al. (2011); (26) Canibe et al. (2001); (28) Rodrigues (2014); (29) Alvarado et al. (2013); (33) Diao et al. (2014); (34) Halas et al. (2009); (35) Halas et al. (2010); (38) Hanczakowska et al. (2011). Fonte: Adaptado de Tonel (2009). 
Tabela IV. Ação dos acidificantes sobre os microrganismos e saúde intestinal de leitões em creche (Action of acidifiers on microorganisms and intestinal health in nursery piglets).

\begin{tabular}{|c|c|c|c|c|c|c|c|c|}
\hline \multirow{2}{*}{ Acidificante } & \multirow{2}{*}{$\begin{array}{l}\text { Idade, dias } \\
\text { (inicial-final) }\end{array}$} & \multicolumn{6}{|c|}{ Microrganismos e atividade microbiana } & \multirow[b]{2}{*}{ FD } \\
\hline & & $\mathrm{BI}$ & $\mathrm{BL}$ & PM & MOP & AGV & $\mathrm{CA}$ & \\
\hline $\begin{array}{l}\text { Formato de } \\
\text { cálcio }\end{array}$ & $18-58$ & & & & & $\bullet(5)$ & & $\boldsymbol{\nabla}(4)(39)$ \\
\hline $\begin{array}{l}\text { Butirato de } \\
\text { sódio }\end{array}$ & $21-58$ & • (40) & & $\bullet(23)$ & $\boldsymbol{\nabla}(23)$ & $\begin{array}{c}\bullet(3) \Delta(11) \\
\nabla(20)\end{array}$ & & $\bullet(19)$ \\
\hline Ácido benzoico & $21-70$ & $\boldsymbol{\Delta}(10) \bullet(33)$ & $\nabla(7) \bullet(33)$ & $\boldsymbol{\nabla}(7)(13)$ & $\begin{array}{c}\nabla(7)(13) \\
\bullet(29)(33) \\
\bullet(21)\end{array}$ & $\begin{array}{c}\Delta(7)(33) \\
\bullet(28)(34) \\
(35)\end{array}$ & $\bullet(13) \nabla(29)$ & $\begin{array}{c}\boldsymbol{\nabla}(7)(12) \\
(21)(27) \\
\bullet(34)\end{array}$ \\
\hline $\begin{array}{l}\text { Diformiato de } \\
\text { potássio }\end{array}$ & $28-63$ & & $\boldsymbol{\nabla}(26)$ & & $\boldsymbol{\nabla}(26)$ & $\boldsymbol{\Delta}(26)$ & & $\boldsymbol{\nabla}(36)$ \\
\hline Ácido fumárico & $10-70$ & & & & $\boldsymbol{\nabla}(17)(37)$ & & & $\boldsymbol{\nabla}(15) \bullet(17)$ \\
\hline
\end{tabular}

Legenda: $\boldsymbol{\Lambda}$ : Aumento $(p<0,05), \mathbf{\nabla}$ : Redução $(p<0,05)$, $\bullet$ Não alterado $(p>0,05)$. BI: Biodiversidade intestinal, BL: Bactérias láticas, PM: População microbiana, MOP: Microrganismos patogênicos, AGV: Ácidos graxos voláteis, CA: Concentração de amônia, FD: Frequência de diarreia.

(3) Biagi et al. (2007); (4) Bosi et al. (2007); (5) Canibe et al. (2008); (7) Guggenbuhl et al. (2007); (10) Torrallardona et al. (2007); (11) Morais (2009); (12) Gheler et al. (2009); (13) Kluge et al. (2006); (15) Ribeiro et al. (2002); (17) Grecco (2014); (19) Costa et al. (2011); (20) Tonel (2009); (21) Papatsiros et al. (2011); (23) Lu et al. (2008); (26) Canibe et al. (2001); (27) Silveira (2014); (28) Rodrigues (2014); (29) Alvarado et al. (2013); (33) Diao et al. (2014); (34) Halas et al. (2009); (35) Halas et al. (2010); (36) Paulicks et al. (2000); (37) Blank et al. (2001); (39) Mazzoni (2004); (40) Castillo et al. (2006). Fonte: Adaptado de Tonel (2009).

até mesmo pelo desafio sanitário encontrado (Gomes et al., 2007; Chiquieri et al., 2009; Gomes et al., 2011). É importante considerar que alguns acidificantes podem contribuir de forma indireta no crescimento tecidual e controle bacteriano, como é o caso do ácido fumárico que atua como fonte energética prontamente disponível, podendo exercer efeito trófico sobre a mucosa do intestino delgado (Braz, 2007). Esse efeito trófico é responsável pelo aumento da superfície de contato e capacidade de absorção, além da rápida recuperação do epitélio intestinal após o desmame (Silva, 2006).

\section{SAÚDE INTESTINAL}

Os benefícios do uso de acidificantes na saúde intestinal dos leitões desmamados vem sendo pesquisados por diversos autores (tabela IV). A diversidade microbiana é uma medida da quantidade dos diferentes microrganismos detectados e, também atua como um indicador da estabilidade da microbiota intestinal (Zoetendal et al., 2004). Uma elevada biodiversidade microbiana pode produzir um efeito benéfico no desempenho animal pois previne a proliferação de grupos simples de bactérias (Jensen et al., 2003).

Bactérias do gênero Escherichia coli são responsáveis por diarreias e queda de peso, além de causadoras de um alto índice de mortalidade e morbidade em leitões lactentes e em creche. Níveis de 0,50\% (Guggenbuhl et al., 2007; Papatsiros et al., 2011) e de 0,75\% (Silveira, 2014; Gheler et al., 2009) de ácido benzoico na dieta apresentaram melhoras significativas na saúde intestinal, reduzindo a incidência de diarreia e populações bacterianas como Escherichia coli no ceco de leitões em creche.

A adição de 1,0\% de ácido fumárico em dietas na fase inicial indicaram uma menor incidência de diarreia em leitões nos 10 primeiros dias do período pósdesmama (Ribeiro et al., 2002). Grecco (2014) conclui que o ácido fumárico exerce ação inibitória sobre a população de coliformes totais e de Escherichia coli. Já em estudo, Blank et al. (2001) relataram que os efeitos benéficos do ácido fumárico sobre a atividade microbiana são fortemente dependentes da capacidade de tamponamento inicial da dieta porém concluem que através do maior aproveitamento dos nutrientes pelo leitão, a quantidade de substrato disponível para a fermentação no intestino delgado é reduzida.O uso de sais de ácidos orgânicos, como o formiato de cálcio e o diformiato de potássio, também tem apresentado resultados positivos na redução da incidência de diarreias em leitões recém-desmamados (Bosi et al., 2007; Paulicks et al., 2000).

\section{DESEMPENHO E DIGESTIBILIDADE DE NUTRIENTES}

$\mathrm{Na}$ tabela $\mathrm{V}$ encontra-se uma síntese dos resultados obtidos sobre o efeito do uso de acidificantes no desempenho zootécnico e digestibilidade dos nutrientes em leitões. Os benefícios do uso de ácido benzoico ao aumentar a altura das vilosidades possibilita maior aderência e captação dos nutrientes para absorção no epitélio intestinal. Assim, diversos estudos apontam para o maior desempenho dos leitões associado à maior digestibilidade dos nutrientes (Guggenbuhl et al., 2007; Torrallardona et al., 2007; Diao et al., 2013). Outras respostas associadas ao ácido benzoico tem sido verificadas como a forte ação antimicrobiana, redução de bactérias gram-negativas em nível intestinal e redução da heterogeneidade do lote (Kluge et al., 2006; Alvarado et al., 2013). O uso do ácido benzoico associado com a fitase previne problemas ósseos (Bühler $e t$ al., 2010)e associado a um probiótico contendo Bacillus cereus var. toyoi, melhora o desempenho dos leitões com aumento no ganho de peso diário e peso vivo final (Papatsiros et al., 2011). Em estudos de digestibilidade, o benzoato de cálcio quando adicionado às dietas de leitões aumenta os coeficientes de digestibilidade de 
Tabela V. Influência dos acidificantes sobre o desempenho zootécnico de leitões em creche (Influence of acidifying up on the nursery piglets's performance).

\begin{tabular}{|c|c|c|c|c|c|}
\hline Acidificante & $\begin{array}{l}\text { Idade, dias } \\
\text { (inicial-final) }\end{array}$ & $\begin{array}{l}\text { Consumo de } \\
\text { ração }\end{array}$ & Ganho de peso & Conversão alimentar & $\begin{array}{c}\text { Digestibilidade dos } \\
\text { nutrientes }\end{array}$ \\
\hline Formato de cálcio & $18-58$ & $\bullet(1)(2)(18) \Delta(5)$ & $\boldsymbol{\nabla}(1) \bullet(2)(18) \Delta(4)(5)$ & $\bullet(1)(2)(18)$ & \\
\hline Butirato de sódio & $21-58$ & $\begin{array}{c}\boldsymbol{\Delta}(1)(7)(8)(23) \\
\bullet(3)(6)(9)(20)(31)\end{array}$ & $\begin{array}{c}\bullet(1)(3)(6)(9)(20)(31) \\
\boldsymbol{\Lambda}(23)\end{array}$ & $\begin{array}{c}\bullet(1)(3)(6)(11)(20) \\
(31) \\
\nabla(9)(23)\end{array}$ & $\boldsymbol{\Delta}(8)(20) \bullet(11)(31)$ \\
\hline Ácido benzoico & $21-70$ & $\begin{array}{c}\boldsymbol{\Delta}(10)(12)(21) \\
(27)(31)(35) \\
\bullet(13)(16)(29)(30) \\
(32)(34)\end{array}$ & $\begin{array}{c}\Delta(7)(10)(12)(13)(21)(27) \\
(29)(31)(35) \bullet(16)(30)(32) \\
(34)\end{array}$ & $\begin{array}{c}\boldsymbol{\nabla}(7)(10)(27)(29) \\
(30)(32) \\
\bullet(12)(13)(16)(21) \\
(31)(34)\end{array}$ & $\begin{array}{c}\boldsymbol{\Delta}(7)(10)(30) \\
(31)(32)\end{array}$ \\
\hline Diformiato de potássio & $28-63$ & $\bullet(13)(16)(24)$ & $\boldsymbol{\Delta}(13)(24) \bullet(16)$ & $\boldsymbol{\nabla}(13)(24)(36) \bullet(16)$ & \\
\hline Ácido fumárico & $10-70$ & $\begin{array}{c}\bullet(14)(15)(17)(22) \\
(25) \\
\boldsymbol{\Delta}(16)(18)\end{array}$ & $\begin{array}{c}\bullet(14)(15)(17)(22)(25) \\
\mathbf{\Lambda}(16)(18)\end{array}$ & $\begin{array}{c}\bullet(14)(15)(17)(16) \\
(18)(22)(25)\end{array}$ & $\bullet(16)(22)$ \\
\hline
\end{tabular}

Legenda: $\boldsymbol{\Lambda}$ : Aumento $(p<0,05) ; \mathbf{\nabla}:$ Redução $(p<0,05) ; \bullet:$ Não alterado $(p>0,05)$.

(1) Partanen et al. (2002); (2) Gottlob et al. (2006); (3) Biagi et al. (2007); (4) Bosi et al. (2007); (5) Canibe et al. (2008); (6) Weber e Kerr, 2008; (7) Guggenbuhl et al. (2007); (8) Le Gall et al. (2009); (9) Piva et al. (2002); (10) Torrallardona et al. (2007); (12) Gheler et al. (2009); (13) Kluge et al. (2006); (14) Gomes et al. (2007); (15) Ribeiro et al. (2002); (16) Miguel (2008); (17) Grecco (2014); (18) Lawlor et al. (2005); (20) Tonel (2009); (21) Papatsiros et al. (2011); (22) Kil et al. (2006); (23) Lu et al. (2008); (24) Htoo e Molares (2012); (25) Gomes et al. (2011); (27) Silveira (2014); (29) Alvarado et al. (2013); (30) Diao et al. (2013); (31) Gräber et al. (2012); (32) Kluge et al. (2011); (34) Halas et al. (2009); (35) Halas et al. (2010). Fonte: Adaptado de Tonel (2009).

matéria seca, orgânica e proteína bruta, além do aumento na digestibilidade ileal de vários aminoácidos essenciais e não essenciais (Mroz et al., 2000).

O butirato de sódio possui respostas contraditórias no desempenho de leitões em creche podendo estar associado principalmente com a composição diferente das dietas e maturidade fisiológica do intestino (Biagi et al., 2007). Mazzoni et al. (2008) afirma que o butirato exerce forte impacto sobre desempenho de crescimento e consumo de ração dos leitões. Porém Biagi et al. (2007) mostra resultados contraditórios, onde o butirato de sódio não influencia no crescimento ou desempenho, mas aumenta o pH e a concentração de amônia cecal. Já o uso do ácido cítrico em dietas para leitões em creche tem apresentado respostas positivas quanto ao ganho diário de peso e eficiência alimentar (Braz, 2007). Entretanto, existem poucos estudos sobre a adiçãode ácido cítrico em dietas para leitões recém-desmamados, mas os existentes mostram que ele melhora a eficiência alimentar de leitões, digestibilidade do cálcio, queda do $\mathrm{pH}$ gástrico, sendo um grande agente antimicrobiano (Ahmed et al. 2014; Gottlob et al. 2005).

O ácido fumárico tem sido amplamente utilizado como acidificante em dietas para leitões em creche. Atualmente, diversas combinações contendo, além de outros ácidos orgânicos, prebioticos, probióticos, enzimas e extratos vegetais são associadas ao uso do ácido fumárico para leitões em creche (Santos, 2010; Corassa et al. 2012).

As associações de ácido fumárico $(1,0 \%)$ com outros ácidos ( $0,5 \%$ de ácido fórmico e $0,1 \%$ de ácido butírico) diminui o ganho de peso dos leitões no período de 15 a 36 dias de idade, embora o uso isolado do ácido fumárico $(0,5 \%)$ para leitões recém-desmamados tenha melhorado o desempenho dos animais nas duas primeiras semanas pós-desmame (Gomes et al., 2007). Em outro estudo, a utilização de ácido fumárico combinada com ácido lático e propionato de cálcio não obteve melhora no desempenho de leitões desmamados aos 15 dias de idade (Gomes et al., 2011). Para Miguel et al. (2011) e Braz (2007) a suplementação a 1,0\% a 3,0\% do ácido fumárico na dieta afetou o consumo de ração e o ganho de peso, não alterando valores de digestibilidade aparente da proteína e matéria seca.

De modo geral, o desempenho zootécnico e a digestibilidade dos nutrientes para leitões alimentados com dietas contendo acidificantes podem não diferir do grupo controle. Esses resultados foram compilados neste estudo para os principais acidificantes utilizados na fase de creche. Entre as possíveis causas apresentadas pelos autores estão as relacionadas ao ambiente como o bom status sanitário do rebanho, à composição de dieta e do acidificante escolhido que, devido a variabilidade na composição de dietas e o alto poder tamponante dos ingredientes impedem a redução do $\mathrm{pH}$ no trato gastrintestinal dos leitões associado a baixas dosagens dos ácidos orgânicos testados (Mroz, 2005; Kil et al., 2011). Os fatores inerentes ao leitão como o maior peso ao desmame e melhor resposta imune no início da fase de creche podem contribuir para a ausência ou não significância de resultados positivos como o uso dos acidificantes. Além disso, o período de creche associado à melhora da resposta imune do leitão pode contribuir para que a resposta ao uso dos acidificantes seja reduzida ao longo de todo o período (Denck et al., 2015).

\section{FORMA DE INCORPORAÇÃO DOS ÁCIDOS NA DIETA}

Os ácidos orgânicos podem ser utilizados em conjunto na forma de blends de ácidos orgânicos como associações de benzoico, butírico, cítrico, fórmico, fumárico, entre outros. Quanto a forma física, podem ser 
elaborados na forma de pó e adicionados à ração, ou líquida e dissolvidas na água de bebida. Os blends também podem ser de ácido orgânico e sais de ácidos orgânicos com diformiato de potássio, formato de cálcio e butirato de sódio. Com o avanço tecnológico, a forma de incorporação dos ácidos orgânicos melhorou nos aspectos de palatabilidade e potencial de dissociação através do processo de micro encapsulamento. Este processo envolve as moléculas de ácido orgânico ou blend com um fina camada de polímeros ou lipídeos e, quando ingeridos pelo animal, os ácidos são dissociados lentamente no intestino delgado, apresentado melhores resultados em relação ao acidificante não protegido (Piva et al., 2007; Grilli et al., 2010).

Existem diferenças consideráveis na forma de ação dos ácidos orgânicos. Assim, cada acidificante pode apresentar benefícios diferentes devido a suas características químicas particulares e também da capacidade acidificante de cada um no trato digestório (Krygierowicz, 2010). Dessa forma, o autor sugere que utilizar misturas de ácidos orgânicos nas rações pode ser mais eficiente do que quando utilizados isoladamente. É o que relata Silva et al. (2002) onde observou que não houve feito significativo na adição dos ácidos fumárico, lático e propionato de cálcio quando utilizados isoladamente sobre o desempenho de leitões, entretanto, quando combinados proporcionaram melhora do desempenho dos animais. Atualmente, estudos apontam para o uso associado de ácidos orgânicos e inorgânicos de forma conjunta, por atuarem em sinergismo podem melhorar o estado sanitário e imunológico associado a maior digestibilidade e absorção dos nutrientes, atuando em conjunto para a melhora no desempenho zootécnico e uniformidade do lote (Kil et al., 2011). Hilgemberg et al. (2015) em um estudo de meta-análise contemplando 113 artigos sobre acidificantes verificou que os blends de ácidos orgânicos são superiores quanto ao ganho de peso de leitões de 21 a 32 dias de idade em relação a ouso isolado de sais orgânicos e ácidos orgânicos na alimentação de leitões pós-desmame.

\section{CONSIDERAÇÕES FINAIS}

O uso de acidificantes em dietas para leitões na fase de desmame e creche melhora a condição sanitária e o desempenho. As ações positivas do uso estão associadas a redução do pH gástrico, controle da microbiota intestinal e estimulo na secreção de enzimas digestivas. Como resultado, os ácidos orgânicos e sais podem melhorar o ganho de peso e a eficiência alimentar. Os ácidos benzoico, fumárico e sais destes ácidos apresentam um maior número de informações na literatura. O uso conjunto de ácidos orgânicos e sais, além dos blendsambos administrados na forma cristalina, livre ou protegidos, apresentam os melhores resultados para leitões em creche.

\section{AGRADECIMENTOS}

Ao Conselho Nacional de Desenvolvimento Científico e Tecnológico e à Fundação Araucária (FA-PR) pelas bolsas de iniciação científica concedidas.

\section{BIBLIOGRAFIA}

Ahmed, S.T.; Hwang, J.A.; Hoon, J.; Mun, H.S. and Yang, C.J. 2014. Comparison of single and blend acidifiers as alternative to antibiotics on growth performance, fecal microflora, and humoral immunity in weaned piglets. Asian-Australasian J Anim Sci, 27: 93-100.

Alvarado, M.A.P.; Cervantes López, J.; Braña Varela, D.; Mariscal Landín, G.y Cuarón lbargüengoytia, J.A. 2013. Ácido benzoico y un producto basado en especies de Bacillus para proteger la productividad de los lechones y al ambiente. Rev Mex Cienc Pec, 4: 447-468.

Biagi, G.; Piva, A.; Moschini, M.; Vezzali, E. and Roth, F.X. 2007. Performance, intestinal microflora, and wall morphology of weanling pigs fed sodium butyrate. J Anim Sci, 85: 1184-1191.

Blank, R.; Sauer, W.; Mosenthin, R.; Zentek, J.; Huang, S. and Roth, S. 2001. Effect of fumaric acid supplementation and dietary buffering capacity on the concentration of microbial metabolites in ileal digesta of young pigs. Can J Anim Sci, 81: 345-353.

Bosi, P.; Sarli, G.; Casini, L.; De Filippi, S.; Trevisi, P.; Mazzoni, M. and Merialdi, G. 2007. The influence of fat protection of calcium formate on growth and intestinal defence in Escherichia coli K88-challenged weanling pigs. Anim Feed Sci Technol, 139: 170-185.

Bosi, P.; Messori, S.; Nisi, I.; Russo, D.; Casini, L.; Coloretti, F.; Schwarzer, K. and Trevisi, P. 2009. Effect of different butyrate supplementations on growth and health of weaning pigs challenged or not with $E$. coli K88. Italian J Anim Sci, 8: 268-270.

Braz, D.B. 2007. Acidificantes como alternativas aos antimicrobianos melhoradores do desempenho de leitões na fase de creche. Dissertação (Mestrado). Universidade de São Paulo. Escola Superior de Agricultura "Luiz de Queiroz". Piracicaba. 79 pp.

Braz, D.; Costa, L.; Berenchtein, B.; Tse, M.; Almeida, V. y Miyada, V. 2011. Acidificantes como alternativa aos antimicrobianos promotores do crescimento de leitões. Arch Zootec, 60: 745-756.

Brumano, G. e Gattás, G. 2009. Alternativas ao uso de antibióticos como promotores de crescimento em rações de aves e de suínos. Rev Eletr Nutrit, 6: 856-875.

Bühler, K.; Liesegang, A.; Bucher, B.; Wenk, C. and Broz, J. 2010. Influence of benzoic acid and phytase in low-phosphorus diets on bone characteristics in growing-finishing pigs. J Anim Sci, 88: 3363-3371.

Canibe, N.; Miettinen, H. and Jensen, B.B. 2008. Effect of adding Lactobacillus plantarum or a formic acid containing-product to fermented liquid feed on gastrointestinal ecology and growth performance of piglets. Livest Sci, 114: 251-262.

Canibe, N.; Steien, S.; Overland, M. and Jensen, B.B. 2001. Effect of $\mathrm{K}$-diformate in starter diets on acidity, microbiota, and the amount of organic acids in the digestive tract of piglets, and on gastric alterations. J Anim Sci, 79: 2123-2133.

Castillo, M.; Martín-Orúe, S.; Roca, M.; Manzanilla, E.; Badiola, I.;Perez, J. and Gasa, J. 2006. The response of gastrointestinal microbiota to avilamycin, butyrate, and plant extracts in early-weaned pigs. J Anim Sci, 84: 2725-2734.

Chamone, J.M.A.; Melo, M.T.P.; Arouca, C.L.C.; Barbosa, M.M.; Souza, F.A. e Santos, D. 2010. Fisiologia digestiva de leitões. Rev Eletr Nutrit, 1353-1363.

Chiquieri, J.; Soares, R.T.R.N.; Lyra, M.S.; Hurtado, V.L.N. e Fonseca, J.B. 2009. Ácidos orgânicos na alimentação de leitões desmamados. Arch Zootec, 58: 609-612.

Corassa, A. 2004. Mananoligossacarídeos, ácidos orgânicos, probióticos e níveis de ácido fólico em dietas para leitões de 21 a 49 dias de idade. Tese (Doutorado). Universidade Federal de Viçosa. Viçosa. 65 pp.

Costa, L.; Berenchtein, B.; Almeida, V.; Tse, M.; Braz, D.; Andrade, C.; Mourão, G. e Miyada, V. 2011. Aditivos fitogênicos e butirato de sódio como promotores de crescimento de leitões desmamados. Arch Zootec, 60: 687-698.

Denck, F.M.; Lehnen, C.R.; Hilgemberg, J.O.; Primieri, C. e Banckes, T.N. 2015. Ácido fumárico na alimentação de leitões pós-desmame e em creche: estudo meta-analítico. XVII Congresso ABRAVES 2015 - Suinocultura em transformação. Anais... Associação Brasileria de Veterinários Especialistas em Suínos. Campinas, SP. pp. 125-127. 
Diao, H.; Zheng, P.; Yu, B.; He, J.; Mao, X.; Yu, J.; Huang, Z.; Dai, L.; Wang, $Q$. and Chen, D. 2013. Effects of benzoic acid on growth performance, serum biochemical parameters, nutrient digestibility and digestive enzymes activities of jejuna digesta in weaner piglets. Chin J Anim Nutr, 25: 768-777.

Diao, H.; Zheng, P.; Yu, B.; He, J.; Mao, X.B.; Yu, J. and Chen, D.W. 2014. Effects of dietary supplementation with benzoic acid on intestinal morphological structure and microflora in weaned piglets. Livest Sci, 167: 249-256.

EFSA. 2013. Scientific opinion on the safety and efficacy of fumaric acid as a feed additive for all animal species. EFSA Panel on additives and products or substances used in animal feed (FEEDAP). European Food Safety Authority. EFSA J, 11: 3102-3116.

Gauthier, R. 2005. Organic acids and essential oils, a realistic alternative to antibiotic growth promoters in poultry. I Forum Internacional de Avicultura. August 17-19, 2005. Foz do Iguaçu, PR. Brazil.

Ghisalberti, E.L. 2002. Secondary metabolites with antinematodal activity. In: Studies in Natural Prod

Gheler, T.R.; Araújo, L.F.; Silva, C.C.D.; Gomes, G.A.; Prata, M.F. e Gomide, C.A. 2009. Uso de ácido benzoico na dieta de leitões. Rev Bras Zootecn, 38: 2182-2187.

Gomes, F.; Fontes, D.; Saliba, E.; Ferreira, W.; Fialho, E.; Silva, F.; Silva, M.; Corrêa, G. e Salum, G. 2007. Ácido fumárico e sua combinação com os ácidos butírico ou fórmico em dietas de leitões recém desmamados. Arq Bras Med Vet Zootec, 59: 1270-1277.

Gomes, F.; Fontes, D.; Vasconcellos, C. e Silva, F. 2011 1. Ácido fumárico e sua combinação com ácido lático ou propionato de cálcio em dietas de leitões recém-desmamados. Arq Bras Med Vet Zootec, 63: 678-686.

Gottlob, R.O.; Groesbeck, C.N.; Tokach, M.D.; Dritz, S.S.; Goodband, R.D.; DeRouchey, J.M.; Nelssen, J.L. and Neill, C.R. 2005. Effects of water-based citric acid on growth performance and water disappearance of weanling pigs. Swine Res: 60-63.

Gottlob, R.; Benz, J.; Groesbeck, C.; Sulabo, R.; Tokach, M.D.; Nelssen, J.L.; Goodband, R.D.; DeRouchey, J.M. and Dritz, S.S. 2006. Effects of dietary calcium formate and malic acid on nursery pig growth performance. Swine Day: 67-71.

Gräber, T.; Kluge, H.; Hirche, F.; Brož, J. and Stangl, G.I. 2012. Effects of dietary benzoic acid and sodium-benzoate on performance, nitrogen and mineral balance and hippuric acid excretion of piglets. Arch Anim Nutr, 66: 227-236.

Grecco, H.A.T. 2014. Acidificantes em dietas de leitões desmamados: desempenho, peso de orgãos, ph, morfometria e microbiota intestinal. Dissertação (Mestrado). Universidade Estadual Paulista Júlio de Mesquita Filho. Botucatu. $65 \mathrm{f}$

Grilli, E.; Messina, M.R.; Tedeschi, M. and Piva, A. 2010. Feeding a microencapsulated blend of organic acids and nature identical compounds to weaning pigs improved growth performance and intestinal metabolism. Livest Sci, 133: 173-175.

Guggenbuhl, P.; Séon, A.; Quintana, A.P. and Nunes, C.S. 2007. Effects of dietary supplementation with benzoic acid (VevoVitall $($ ) ) on the zootechnical performance, the gastrointestinal microflora and the ileal digestibility of the young pig. Livest Sci, 108: 218-221.

Halas, D.; Hansen, C.F.; Hampson, D.J.; Mullan, B.P.; Kim, J.C.; Wilson, R.H. and Pluske, J.R. 2010. Dietary supplementation with benzoic acid improves apparent ileal digestibility of total nitrogen and increases villous height and caecal microbial diversity in weaner pigs. Anim Feed Sci Technol, 160: 137-147.

Halas, D.; Hansen, C.F.; Hampson, D.J.; Mullan, B.P.; Wilson, R.H. and Pluske, J.R. 2009. Effect of dietary supplementation with inulin and/ or benzoic acid on the incidence and severity of post-weaning diarrhoea in weaner pigs after experimental challenge with enterotoxigenic Escherichia coli. Arch Anim Nutr, 63: 267-280.

Hanczakowska, E.; Szewczyk, A. and Okon, K. 2011. Caprylic, capric and/or fumaric acids as antibiotic replacements in piglet feed. Ann Anim Sci, 11: 115-124.

Hilgemberg, J.O.; Denck, F.M.; Primieri, C.; Banckes, T.N.; Sieklicki, F. e Lehnen, C.R. 2015. Uso de ácidos orgânicos e sais na alimentação de leitões em pós-desmame: uma meta-análise. XXIV Encontro Anual de Iniciação Científica - UEPG.

Htoo, J.K. and Molares, J. 2012. Effects of dietary supplementation with two potassium formate sources on performance of 8 - to $22-\mathrm{kg}$ pigs. J Anim Sci, 90: 346-349.

Jensen, B.B.; Højbjerg, O.; Mikkelsen, L.; Hedemann, M.S. and Canibe, N. 2003. Enhancing intestinal function to treat and prevent intestinal disease. $9^{\text {th }}$ International Symposium on Digestive Physiology of Pig. Banff, Alberta. pp. 14-18.

Kil, D.Y.; Piao, L.G.; Long, H.F.; Lim, J.S.; Yun, M.S.; Kong, C.S.; Ju, W.S.; Lee, H.B. and Kim, Y.Y. 2006. Effects of organic or inorganic acid supplementation on growth performance, nutrient digestibility and white blood cell counts in weanling pigs. Asian Australas J Anim Sci, 19: 252-261.

Kil, D.Y.; Kwon, W.B. and Kim, B.G. 2011 . Dietary acidifiers in weanling pig diets: a review. Rev Colomb Cienc Pec, 24: 231-247.

Kirchgessner, M. and Roth, F. 1988. Energy value of organic acids in the rearing of piglets and the fattening of pigs. Übersichten zur Tierernährung, 16: 93-108.

Kluge, H.; Broz, J. and Eder, K. 2006. Effect of benzoic acid on growth performance, nutrient digestibility, nitrogen balance, gastrointestinal microflora and parameters of microbial metabolism in piglets. J Anim Physiol Anim Nutr, 90: 316-324.

Kluge, H., Brož, J. and Stangl, G.I. 2011. Efficacy of benzoic acid and sodium-benzoate in weaned piglets. BOKU-Symposium Tierernährung. pp. 115-120.

Knarreborg, A.; Miquel, N.; Granli, T. and Jensen, B.B. 2002. Establishment and application of an in vitro methodology to study the effects of organic acids on coliform and lactic acid bacteria in the proximal part of the gastrointestinal tract of piglets. Anim Feed Sci Technol, 99: 131-140

Krygierowicz, E.C. 2010. Taxa linear de tamponamento como estimadora de efeitos nutricionais da acidificação da dieta para leitões. Dissertação (Mestrado). Universidade Federal do Paraná. Curitiba. 64 pp.

Lanferdini, E.; Andretta, I.; Lehnen, C.R.; Melchior, R.; Silva, M.F.R. e Garcia, G.G. 2013. Digestibilidade de dietas e metabolismo de suínos alimentados com dietas contendo extratos cítricos. Arch Zootec, 62: 307-310.

Lawlor, P.G.; Lynch, P.B. and Caffrey, P.J. 2005. Effect of creep feeding, dietary fumaric acid and level of dairy product in the diet on postweaning pig performance. Irish J Agric Food Res, 44: 45-55.

Le Gall, M.; Gallois, M.; Sève, B.; Louveau, I.; Holst, J.J.; Oswald, I.P.; Lallès, J.-P. and Guilloteau, P. 2009. Comparative effect of orally administered sodium butyrate before or after weaning on growth and several indices of gastrointestinal biology of piglets. Br J Nutr, 102: 1285-1296.

Lee, D.; Liu, S.; Chen, Y.; Wang, R.; Lin, S. and Weng, C. 2007. Effects of diets supplemented with organic acids and nucleotides on growth, immune responses and digestive tract development in weaned pigs. $J$ Anim Physiol Anim Nutr, 91: 508-518.

Lu, J.; Zou, X. and Wang, Y. 2008. Effects of sodium butyrate on the growth performance, intestinal microfl ora and morphology of weanling pigs. J Anim Feed Sci, 17: 557-568.

Machinsky, T.G.; Kessler, A.M.; Ribeiro, A.M.L.; Moraes, M.L.; Silva, I.C.M. e Cortés, M.E.M. 2010. Digestibilidade de nutrientes e balanço de Ca e $\mathrm{P}$ em suínos recebendo dietas com ácido butírico, fitase e diferentes níveis de cálcio. Cienc Rural, 40: 2350-2355.

Mazzoni, M.; Le Gall, M.; De Filippi, S.; Minieri, L.; Trevisi, P.; Wolinski, J.; Lalatta-Costerbosa, G.; Lallès, J.-P.; Guilloteau, P. and Bosi, P. 2008. Supplemental sodium butyrate stimulates different gastric cells in weaned pigs. J Nutr, 138: 1426-1431.

Mazzoni, M.L.C., G.; Casini, L.; Petrosino, G.; Trevisi, P.; De Filippi, S. e Bosi, P. 2004. La morfologia dello stomaco come parametro di valutazione dell'impiego di acidificanti nella dieta del suino in svezzamento. LVIII Convegno annuale. Anais... Atti della Società Italiana delle Scienze Veterinarie. Gorizia. pp. 79-480. 
Miguel, W.C. 2008. Suplementação de acidificantes em rações de leitões desmamados: desempenho e digestibilidade. Dissertação (Mestrado). Faculdade de Medicina Veterinária e Zootecnia. Universidade de São Paulo. Pirassurunga. 54 pp.

Miguel, W.C.; Neto, M.A.D.T.; Berto, D.A.; Kobashigawa, E. e Gandra, E.R.S. 2011 . Suplementação de acidificantes em rações de leitões desmamados: desempenho e digestibilidade. Brazilian J Vet Res Anim Sci, 48: 141-146.

Morais, S.C.F. 2009. Utilização de dois teores de butirato no regime de desmame do leitão: crescimento, digestibilidade, fisiologia digestiva. Dissertação (Mestrado). Universidade Técnica de Lisboa. Lisboa. 62 pp.

Mroz, Z. 2005. Organic acids as potential alternatives to antibiotic growth promoters for pigs. Adv Pork Prod, 16: 169-182.

Mroz, Z.; Jongbloed, A.W.; Partanen, K.H.; Vreman, K.; Kemme, P.A. and Kogut, J. 2000. The effects of calcium benzoate in diets with or without organic acids on dietary buffering capacity, apparent digestibility, retention of nutrients, and manure characteristics in swine. $J$ Anim Sci, 78: 2622-2632.

Papatsiros, V.G.; Tassis, P.D.; Tzika, E.D.; Papaioannou, D.S.; Petridou, E.; Alexopoulos, C. and Kyriakis, S.C. 2011. Effect of benzoic acid and combination of benzoic acid with a probiotic containing Bacillus cereus var. Toyoi in weaned pig nutrition. Polish J Vet Sci, 14: 117-125.

Partanen, K.; Siljander-Rasi, H.; Alaviuhkola, T.; Suomi, K. and Fossi, M. 2002. Performance of growing-finishing pigs fed medium-or high-fibre diets supplemented with avilamycin, formic acid or formic acid-sorbate blend. Livest Prod Sci, 73: 139-152.

Partanen, K.H. and Mroz, Z. 1999. Organic acids for performance enhancement in pig diets. Nutr ResRev, 12: 117-145.

Paulicks, B.; Roth, F. and Kirchgessner, M. 2000. Effects of potassium diformate (Formi ${ }^{\circledR}$ LHS) in combination with different grains and energy densities in the feed on growth performance of weaned piglets. J Anim Physiol Anim Nut, 84: 102-111.

Piva, A.; Morlacchini, M.; Casadei, G.; Gatta, P.P.; Biagi, G. and Prandini, A. 2002. Sodium butyrate improves growth performance of weaned piglets during the first period after weaning. Italian J Anim Sci, 1:35-42.

Piva, A.; Grilli, E.; Fabbri, L.; Pizzamiglio, V. and Campani, I. 2007. Free versus microencapsulated organic acids in medicated or not medicated diet for piglets. Livest Sci, 108: 214-217.

Pupa, J.M.R. 2008. Saúde intestinal dos leitões: o papel de alguns agentes reguladores. I Simpósio Brasil Sul de Suinocultura. Anais... I Simpósio Brasil Sul de Suinocultura. Embrapa Suínos e Aves. Chapecó, SC. pp. 13-27.

Ribeiro, P.; Kronka, R.; Thomaz, M.; Soto, W.C.; Gomes Silva, L.; Kronka, S. e Hannas, M. 2002. Adição do ácido fumárico nas rações de suínos e seus efeitos nas fases inicial, crescimento e terminação. Ars Vet, 18: 70-77

Rodrigues, L.M.M., D.N.; Silveira, H.; Barbosa, J.A.; Lima Neto, T.O.A.; Junqueira, M.R.; Hermes, R.G. and Cantarelli, V.S. 2014. Effects of benzoic acid on ph, volatile fatty acids production and intestinal morphology of piglets on nursery phase. Fórum Internacional de Suinocultura. Anais... XII Fórum Internacional de Suinocultura. Concórdia-SC. pp.117-118.

Santos, C.M.R. 2010. Efeito da utilização de óleos essenciais e ácidos orgânicos microencapsulados na alimentação do leitão: crescimento, digestibilidade, fisiologia digestiva. Dissertação (Mestrado). Instituto Superior de Agronomia. Lisboa. $72 \mathrm{f}$.

Silva, G. 2004. Digestibilidade ileal de aminoácidos de soja micronizada e de farelo de soja para suinos e avaliação de acidificantes em dietas para leitões. Dissertação (Mestrado). Universidade Federal de Viçosa. Viçosa. 96 pp.

Silva, M.C.; Lima, J.A.F. e Fialho, E.T. 2002. Efeito da adição de acidificantes e suas combinações na alimentação de leitões desmamados sobre o desempenho. $39^{\circ}$ Reunião Anual da Sociedade Brasileira de Zootecnia. Anais...Sociedade Brasileria de Zootecnia. Santa Maria. Silva, G.A. da; Rorig, A.; Schmidt, J.M. e Prado Guirro, E.C.B. 2014. Impacto do desmame no comportamento e bem-estar de leitões: revisão de literatura. Veterinária em Foco, 12: 32-48.

Silveira, H. 2014. Ácido benzoico para leitões na fase inicial: avaliação in vivo e ex vivo. Tese (Doutorado). Universidade Federal de Lavras. Lavras. $121 \mathrm{pp}$.

Spreeuwenberg, M.; Verdonk, J.; Gaskins, H. and Verstegen, M. 2001. Small intestine epithelial barrier function is compromised in pigs with low feed intake at weaning. J Nutr, 131: 1520-1527.

Suiryanrayna, M.V. and Ramana, J. 2015. A review of the effects of dietary organic acids fed to swine. J Anim Sci Biotechnol, 6: 45.

Suryanarayana, M.; Suresh, J. and Rajasekhar, M. 2015. A review of the effects of dietary organic acids fed to swine. J Anim Sci Biotechnol, 6: 45-56.

Tonel, I.S.P.A. 2009. Efeito da utilização de butirato de sódio na digestibilidade, actividade fermentativa e morfologia intestinal de leitões desmamados. Dissertação (Mestrado). Instituto Superior de Agronomia Universidade Técnica de Lisboa. Lisboa. 58 pp.

Torrallardona, D.; Badiola, I. and Broz, J. 2007. Effects of benzoic acid on performance and ecology of gastrointestinal microbiota in weanling piglets. Livest Sci, 108: 210-213.

Van Immerseel, F.; Fievez, V.; De Buck, J.; Pasmans, F.; Martel, A.; Haesebrouck, F. and Ducatelle, R. 2004. Microencapsulated short-chain fatty acids in feed modify colonization and invasion early after infection with Salmonella enteritidis in young chickens. Poult Sci, 83: 69-74.

Vente-Spreeuwenberg, M.A.M.; Verdonk, J.M.A.J.; Bakker, G.C.M.; Beynen, A.C. and Verstegen, M.W.A. 2004. Effect of dietary protein source on feed intake and small intestinal morphology in newly weaned piglets. Livest Prod Sci, 86: 169-177.

Vilas Boas, A.D.C. 2014. Suplementação de ácidos orgânicos em dietas para leitões na fase de creche. Produção Animal Sustentável. Dissertação (Mestrado). Instituto de Zootecnia. Agência Paulista de Tecnologia dos Agronegócios. Nova Odessa. 70 pp.

Weber, T.E. and Kerr, B.J. 2008. Effect of sodium butyrate on growth performance and response to lipopolysaccharide in weanling pigs. $J$ Anim Sci, 86: 442-450.

Zoetendal, E.G.; Collier, C.T.; Koike, S.; Mackie, R.I. and Gaskins, H.R. 2004. Molecular ecological analysis of the gastrointestinal microbiota: a review. J Nutr, 134: 465-472. 